\title{
The value of customer cocreated knowledge during the innovation process
}

Citation for published version (APA):

Mahr, F. D., Lievens, A., \& Blazevic, V. (2014). The value of customer cocreated knowledge during the innovation process. Journal of Product Innovation Management, 31(3), 599-615. https://doi.org/10.1111/jpim.12116

Document status and date:

Published: 01/05/2014

DOI:

10.1111/jpim.12116

Document Version:

Publisher's PDF, also known as Version of record

Document license:

Taverne

Please check the document version of this publication:

- A submitted manuscript is the version of the article upon submission and before peer-review. There can be important differences between the submitted version and the official published version of record.

People interested in the research are advised to contact the author for the final version of the publication, or visit the DOI to the publisher's website.

- The final author version and the galley proof are versions of the publication after peer review.

- The final published version features the final layout of the paper including the volume, issue and page numbers.

Link to publication

\footnotetext{
General rights rights.

- You may freely distribute the URL identifying the publication in the public portal. please follow below link for the End User Agreement:

www.umlib.nl/taverne-license

Take down policy

If you believe that this document breaches copyright please contact us at:

repository@maastrichtuniversity.nl

providing details and we will investigate your claim.
}

Copyright and moral rights for the publications made accessible in the public portal are retained by the authors and/or other copyright owners and it is a condition of accessing publications that users recognise and abide by the legal requirements associated with these

- Users may download and print one copy of any publication from the public portal for the purpose of private study or research.

- You may not further distribute the material or use it for any profit-making activity or commercial gain

If the publication is distributed under the terms of Article $25 \mathrm{fa}$ of the Dutch Copyright Act, indicated by the "Taverne" license above, 


\title{
The Value of Customer Cocreated Knowledge during the Innovation Process
}

\author{
Dominik Mahr, Annouk Lievens, and Vera Blazevic
}

Customer cocreation during the innovation process has recently been suggested to be a major source for firms' competitive advantage. Hereby, customers actively engage in a firm's innovation process and take over innovation activities traditionally performed by a firm's employees. Despite its suggested importance, previous research has revealed contradictory findings regarding its impact, the nature of involved customers, and the channels of communication that enable cocreation. To provide a more fine-grained picture, customer cocreated knowledge is first delineated into its key value dimensions of relevance, novelty, and costs, and then their impact on various innovation outcomes is investigated. Next, the study examines the antecedent role of customer determinants; that is, lead user characteristics and customer-firm closeness, on these knowledge value dimensions. Finally, we explore how these effects are moderated by the type of communication channel used. An empirical validation of the conceptual model is performed by means of survey data from 126 customer cocreation projects. The data analysis indicates that customer cocreation is most successful for the creation of highly relevant but moderately novel knowledge. Cocreation with customers who are closely related to the innovating firm results in more highly relevant knowledge at a low cost. Yet, cocreation with lead users produces novel and relevant knowledge. These effects are contingent on the richness and reach of the communication channels enabling cocreation. Overall, the findings shed light on opportunities and limitations of customer cocreation for innovation and reconcile determinants originating in relationship marketing and innovation management. At the same time, managers obtain recommendations for selecting customers and communication channels to enhance the success of their customer cocreation initiatives.

\section{Introduction}

$\mathrm{M}$ any firms aim to benefit from the knowledge, skills, and resources of their customers by jointly creating new products. Customers, as current and future buyers, are the most important external source of knowledge for the innovation process (Eurostat, 2008; Prahalad and Ramaswamy, 2004). Firms may benefit from this source by engaging them in customer cocreation where customers coproduce knowledge that is valuable for the firm's innovation process. This occurs when customers actively engage in the development of new products and take over activities traditionally executed by the firm (Fuchs and Schreier, 2011; Nambisan and Baron, 2009; O'Hern and Rindfleisch, 2010; Piller and Ihl, 2009; von Hippel, 2005). For example, the customers of Cisco develop ideas for a new business unit while Cisco supports the development process by granting access to financial resources and their

Address correspondence to: Dominik Mahr, Department of Marketing \& Supply Chain Management, School of Business and Economics, Maastricht University, P.O. Box 616, 6200 MD Maastricht, the Netherlands. E-mail: d.mahr@maastrichtuniversity.nl. Tel: 31-43-38-83855. employees. Firms invest heavily in communication processes that may facilitate customer cocreation activities and ultimately firms' growth and profitability (EIU, 2009). Yet, previous research has also argued that customers cannot contribute or even hamper the innovation process because they lack the imagination of new products that do not yet exist (Christensen and Bower, 1996; Knudsen, 2007; Magnusson, 2009). These conflicting arguments challenge the effectiveness of a firm's investment in customer cocreation initiatives (Hoyer, Chandy, Dorotic, Krafft, and Singh, 2010). Therefore, managers need a better understanding of the conditions under which customer cocreation leads to successful innovations.

Previous research in services marketing (e.g., Alam, 2002) and innovation management (e.g., von Hippel, 2005) has dealt with the impact of customer involvement on innovation success. Most studies argue that customers possess unique knowledge about their preferences (e.g., Poetz and Schreier, 2012; Prahalad and Ramaswamy, 2004), and so their involvement increases success in terms of product-customer need fit (Alam, 2002), profit (Lau, Tang, and Yam, 2010), or market share (Joshi and Sharma, 2004). In particular, the involvement of 
customers with lead user characteristics who face needs ahead of the majority of the market may result in innovative and profitable new products (Franke, von Hippel, and Schreier, 2006; Morrison, Roberts, and Midgley, 2004). Yet, lead user-driven innovations may not be representative for the majority of customers and may suffer from low adoption rates questioning the usefulness of involving such customers (Magnusson, 2009). Moreover, the involvement of customers who possess close relationships with the innovating firm eases the communication of novel ideas (Hansen, 1999). However, such relationship closeness may lead to a knowledge overlap inhibiting the creation of surprising new insights (Granovetter, 1973).

Besides these ambiguous arguments on how customer characteristics drive the outcomes of cocreation activities, there is also scant research on the investment required to implement such activities. The identification of appropriate customer cocreators and their integration demands significant investments in terms of time and money (Alam,

\section{BIOGRAPHICAL SKETCHES}

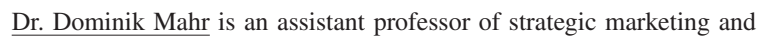
innovation management at School of Business and Economics, Maastricht University, the Netherlands. His research interests are in open innovation, customer cocreation, digital media, knowledge creation, health care, and strategic marketing. His publications have appeared in journals such as Research Policy, Journal of Service Research, BMJ Quality \& Safety (previously Quality \& Safety in Health Care), Health Policy, and Journal of Service Management.

Prof. Dr. Annouk Lievens is professor and chairman of the Marketing Department at the Faculty of Applied Economic Sciences, University of Antwerp, Belgium. Her research interests/activities center on service innovation management, marketing interfaces during new service development, knowledge creation, and organizational communication (i.e., communication networks) during open innovation and within digital platforms. She has published in journals such as the International Journal of Service Industry Management, Journal of Product Innovation Management, European Journal of Marketing, Journal of Service Research, Journal of Management Studies, The International Journal of Bank Marketing, Journal of Business Research, Journal of the Academy of Marketing Science, International Journal of Management Reviews, and Research Policy.

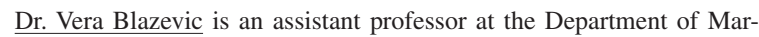
keting, Institute for Management Research at Radboud University Nijmegen, the Netherlands, and a visiting professor at the Technology and Innovation Management Group at RWTH Aachen, Germany. She received her M.Sc. and Ph.D. from Maastricht University, the Netherlands. Her research interests include customer participation in innovation and services and the integration of sustainability in open innovation. Her work has been published in Journal of Marketing, Journal of Service Research, Journal of the Academy of Marketing Science, Journal of International Marketing, Journal of Business Research, and Journal of Service Management.
2002; Luethje and Herstatt, 2004). Scholars tend to emphasize the benefits of customer cocreation such as the novelty or quality of the ideas produced, while the risks and costs involved in establishing cocreation processes remain underresearched (Carbonell, Rodriguez-Escudero, and Pujari, 2009; Hoyer et al., 2010). Yet, particularly when using face-to-face communication channels, costs might outweigh the benefits and force firms to eventually abandon their cocreation activities (Olson and Bakke, 2001). New digital communication channels that can reach many customers at low costs may provide an opportunity to limit financial investment (Sawhney, Verona, and Prandelli, 2005). For example, via its website, Dell collected more than 10,000 suggestions and assessments from its customers for product innovation (Poetz and Schreier, 2012). In spite of the communication channel's pivotal impact in enabling the customer cocreation process, investigations have usually focused on one specific channel rather than comparing several at once.

To address these mixed findings and research gaps mentioned above, this research examines the impact of customer cocreation, the characteristics of involved customers, and the communication channels enabling cocreation between customers and firms during the innovation process. This provides a more fine-grained picture by first identifying knowledge benefits (relevance and novelty) and costs as the main value dimensions of customer cocreated knowledge and then investigating the following questions:

- How do these value dimensions of customer cocreated knowledge impact customer, learning-related, and financial innovation outcomes?

- To what extent do key customer determinants, lead user characteristics, and customer-firm closeness affect these knowledge value dimensions?

- How is the relationship between customer determinants and cocreated knowledge influenced by the choice of communication channels?

Doing so addresses calls for research on the empirical investigation of drivers and outcomes of customer cocreation (Di Benedetto, 2012; Hoyer et al., 2010; MSI, 2010).

In turn, this study makes three main research contributions. First, it enriches the emerging research on the service-dominant logic by developing a framework for customer cocreation of knowledge during the innovation process (Vargo and Lusch, 2004). The empirical test of the conceptualization of multiple knowledge dimensions probes into the distinct effects of benefits and costs of customer cocreation. This contradicts most prior studies 
which have taken either an exclusively positive or negative stance on customer cocreation and its impact on innovation outcomes (Christensen and Bower, 1996; Prahalad and Ramaswamy, 2004). Second, the servicedominant logic also offers an overarching perspective to accommodate the theoretical streams of innovation management (von Hippel, 1986) and relationship marketing (Morgan and Hunt, 1994) that have posited different antecedents of customer cocreation (Piller and Ihl, 2009). This study disentangles the effects of lead user characteristics and relationship closeness on the knowledge value dimensions. These findings also provide managerial recommendations on how to match customer selection criteria with innovation outcomes. Third, this research enriches communication research by examining cocreation processes crossing firm boundaries rather than occurring within a firm. The findings demonstrate how the communication channels' reach and richness enhance or reduce the effectiveness of customer determinants on the knowledge value dimensions (Daft and Lengel, 1986; Sproull and Kiesler, 1986). The contrary effects of communication channels, such as personal meetings, phone, and email, advocate the selection of cocreation channels according to the nature of the customer.

\section{Theoretical Framework: Customer Cocreation}

Traditionally, firms have viewed customers as passive recipients and targets of their offerings. Surveys, interviews, or other market research tools have supplied firms with information about customer needs to feed firms' innovation process and modify their products. Techniques such as quality function deployment support firms in translating need-related information into product requirements (Griffin and Hauser, 1993). More recently, scholars and practitioners alike have recognized customers as active partners who can participate in firms' valuecreation processes and are empowered to develop solutions themselves addressing their needs (Franke, Schreier, and Kaiser, 2010; Fuchs and Schreier, 2011; Nambisan and Baron, 2009; Prahalad and Ramaswamy, 2004; Sawhney et al., 2005). Scholars in marketing and innovation management identify two key reasons for this paradigm shift from value creation for to value creation with customers (Vargo and Lusch, 2004).

First, new technological opportunities enable customers to be highly informed (Prahalad and Ramaswamy, 2004) and offer wider opportunities for firms to integrate customers' expertise, for example, through firm-hosted communities (Nambisan and Nambisan, 2008). Second, the need for a continuous flow of innovation has even increased, which entails a higher demand for need- and solution-related information. Cocreation enables customers to contribute unique knowledge about their usage through continuous participation in the firm's innovation process (Nambisan and Baron, 2009; von Hippel, 2005). The participation transforms customers into a knowledge resource through which firms can improve their innovation performance and competitiveness (Vargo and Lusch, 2004).

\section{Definition and Key Components of Customer Cocreation}

Building on the foundational premises of the servicedominant logic (Vargo and Lusch, 2008) and prior research (e.g., Blazevic and Lievens, 2008; Jaworski and Kohli, 2006; Nambisan and Baron, 2009), this research defines customer cocreation as customer coproduction of knowledge that is valuable for the firm's innovation process. This definition integrates three central components of the service-dominant logic. First, it acknowledges the central role of using knowledge to develop innovations and achieve a competitive advantage (Madhavan and Grover, 1998; Vargo and Lusch, 2008). Customer cocreation includes customers as resources outside of the firm's boundaries. These external resources cannot be controlled like internal resources and may require distinct mechanisms for knowledge transfer, data protection, and incentivizing (O’Hern and Rindfleisch, 2010).

The second component of the definition pertains to the value-in-use view which argues that value is always determined by the beneficiary (Vargo and Lusch, 2008). Previous literature has demonstrated how customers may benefit from cocreation, for example, through an increased sense of belonging to a community (Nambisan and Baron, 2009), a stronger feeling of accomplishment (Franke et al., 2010), or a better fit with their own needs (Piller and Ihl, 2009). This study focuses on the benefits for firms similar to earlier studies (e.g., Blazevic and Lievens, 2008; Lau et al., 2010; Magnusson, 2009; Sawhney et al., 2005). A firm perspective implies that the value of knowledge depends on how the innovating firm as the beneficiary can use it in a specific situation at a certain moment in time.

The third element concerns customers' participation in the creation of valuable knowledge, termed coproduction, which is nested in the cocreation logic (Vargo and Lusch, 2008). Coproduction outcomes vary significantly across customers (Blazevic and Lievens, 2008). Firms deliberately select participating customers on the basis of their 
individual qualities such as their expertise (Schreier and Pruegl, 2008) or the qualities of the firm's relationship with them, such as trust (Morgan and Hunt, 1994). This participation is activated by communication at the firmcustomer interface (Ballantyne, 2004). Through iterative customer-company interactions, both sides can combine their knowledge, enhance their shared understanding, and learn about the other's needs (Sawhney et al., 2005). This interactive method differs from traditional market research techniques, which are often more static and do not allow for the emergence of unexpected needs or ideas, especially important in dynamic, unpredictable environments (O’Hern and Rindfleisch, 2010).

\section{Value Dimensions of Customer Cocreated Knowledge}

Firms attempt to develop knowledge valuable for the innovation tasks at hand (Madhavan and Grover, 1998). Innovation is typically carried out in projects (Joshi and Sharma, 2004), and so valuable knowledge needs to support the achievement of project objectives. Previous studies of customer cocreation have varied in the actual value of knowledge they refer to such as novel insights (e.g., von Hippel, 2005), usefulness (e.g., Alam, 2002), or the need for minimal physical efforts (e.g., Sawhney et al., 2005). This research is enriched through the consideration of the different dimensions by using a structural approach that decomposes knowledge value into several lower-order dimensions (Moenaert and Souder, 1996). In line with classic economic theory, knowledge value is measured as "the relative balance between costs and considered usefulness" (Bailey and Pearson, 1983, p. 542). Innovation team members assess the value of customer cocreated knowledge by weighing the benefits against the costs associated with its development and use.

Research on organizational knowledge creation during innovation has previously pointed toward the benefits of knowledge obtained through exploration and exploitation (March, 1991). Explorative activities, including discovery and experimentation, lead to knowledge that provides new insights, unique inspirations, and a broad range of opinions and ideas, that is, knowledge novelty (Im and Workman, 2004; Kristensson, Magnusson, and Matthing, 2002). It is usually difficult to detect but enables the development of new and distinctive products that are hard to imitate for competitors. On the other hand, exploitative activities such as implementation and refinement produce knowledge that is appropriate for the particular project, provides details related to the tasks, and is easy to understand and implement, that is, knowledge relevance (Im and Workman, 2004; Kristensson et al., 2002). It is typically implementable without further transformation and speeds up project implementation. Both dimensions may contribute differently to innovation success (Poetz and Schreier, 2012).

Whereas benefits increase the value of knowledge, it may be diminished by the high costs of using the knowledge. Knowledge costs represent the temporal and monetary efforts required from firms to create and access knowledge. Employees spend a considerable amount of time on the identification of appropriate customers as well as on the management and monitoring of interactions with them (Piller and Ihl, 2009). The costs of cocreation also depend on the complexity of the knowledge, the difficulty in transferring it, and the scarcity of customers who often require an adequate compensation. Overall, the costs for knowledge transfers vary significantly across projects and may explain why customers are involved in development efforts or not (Hoyer et al., 2010; von Hippel, 2005). Even though practitioners and scholars consider expenditures to be a key criterion for engaging in shared activities (Alam, 2002; Eurostat, 2008), studies on the utility of knowledge often ignore them (Moenaert and Souder, 1996).

In summary, the value of customer cocreated knowledge increases with greater benefits in terms of novelty and relevance and decreases with greater costs. These knowledge value dimensions are not unique to the customer cocreation context which strengthens their generalizability and the comparison of findings across different contexts. Yet, the dimensions' conceptualization and the following argumentation remain specific to customer cocreation.

\section{Hypotheses Development}

\section{Customer Cocreated Knowledge and Innovation Success}

The firm's aim is the development of knowledge for new products that are superior in the market and financially successful (Madhavan and Grover, 1998; Slater and Narver, 1995). Market/financial success may encompass financial outcomes such as profit and revenues, as well as market outcomes such as sales and market shares (Veldhuizen, Hultink, and Griffin, 2006). However, success can have several meanings and thus should be assessed through a multidimensional set of measures (e.g., Griffin and Page, 1996). Practitioners and scholars generally agree on the importance of customer-related outcomes, measured for example by customer satisfac- 
tion and product-customer need fit (i.e., customer acceptance) (Griffin and Page, 1996). At the same time, firms may also profit from innovation activities that produce employee and organizational learning for future projects (i.e., learning success).

Impact of customer acceptance and learning success. The innovation project's ultimate goal, to achieve high financial and market performance, depends on both customer acceptance and learning success (Slater and Narver, 1995). First, the assumption that a new product matching the needs of customers is more likely to be purchased represents a central tenet of innovation research. Satisfied customers tend to talk positively about new products (Hoyer et al., 2010), which, in turn, may increase profitability because new products require lower investments in customer acquisition and promotion. The improvement of customer-related factors, such as customer satisfaction or product's quality as perceived by the customers, enhances a firm's business performance (Henard and Szymanski, 2001; Jaworski and Kohli, 1993). Second, even if a product does not match customers' needs, a firm may benefit from learning during the product's development; learning from innovation experience and improving the firm's organizational capabilities can ensure long-term innovation success and have a positive impact on the firm's performance (Moorman and Slotegraaf, 1999). As a result, it is hypothesized:

\section{H1: (a) Customer acceptance and (b) learning success lead to greater market/financial success.}

Impact of knowledge relevance. Customer cocreation of relevant knowledge is expected to match the project's requirements and to detail the project tasks to relate positively to innovation outcomes (Moenaert and Souder, 1996). More specifically, relevant knowledge may accurately describe market demands and customer needs that project members can integrate into the specifications of new products through intense interactions (Hoyer et al., 2010). Compared with other knowledge sources, feedback provided by customers often offers a better match with the tasks and is available when needed. This ensures a timely new product launch and encourages innovation adoption (Franke and Shah, 2003). Products that closely match customer needs increase customer satisfaction and the likelihood of adoption (Henard and Szymanski, 2001). Moreover, knowledge which is closely related to the project's goals and tasks increases learning outcomes for the organization. During the course of the project, members gain experience and additional insights that update their knowledge base for subsequent projects (Blazevic and Lievens, 2004). Research on the absorption of external information and organizational learning demonstrates that knowledge created with external sources such as customers must relate to and overlap with prior knowledge; only then can firms recognize the value of the new knowledge and assimilate it (Cohen and Levinthal, 1990). Thus, the following hypothesis is deduced:

\section{H2: Customer cocreation of relevant knowledge leads to greater (a) customer acceptance and (b) learning success.}

Impact of knowledge novelty. The creation and use of unique and surprising insights is critical to the development of new products (Amabile, Conti, Coon, Lazenby, and Herron, 1996; Moenaert and Souder, 1996) but it affects innovation outcomes in different ways. For a start, customers often possess very creative ideas and insights that greatly differ from the ones present inside a firm (Franke et al., 2010). Through their interactions, firms and customers iteratively exchange their knowledge about needs and solution requirements (von Hippel, 2005). Both parties recombine their complementary knowledge in an imaginative way and try out new solutions. For example, firms provide customers with tool kits to experiment with new product configurations. Within a given solution space, customers are enabled to develop new product ideas matching their needs (Franke and Piller, 2004). Firms give customers feedback on these ideas and, at the same time, obtain solutions that they often have not thought of beforehand (Kristensson et al., 2002). Integrating this novel knowledge produces superior and distinctive product features that increase the likelihood of customer adoption (Henard and Szymanski, 2001; Im and Workman, 2004).

On the other hand, customers may devise such original ideas that provide input for the development of entirely new product categories. Many customers resist the adoption of new products and technologies which do not immediately match their needs (Christensen and Bower, 1996). Also, extremely novel features and functionalities are often difficult to understand and require consumers to exert hard work to become familiar with them. These functionalities demand fundamental changes in customers' established routines that may cause customer dissatisfaction (Alba and Hutchinson, 1987). Consequently, customer cocreation aiming at a moderate level of knowledge novelty entails greater customer acceptance than that which attains low and high degrees of novelty. These cocreation activities typically include 
some trial and error to discover customer needs but avoid excessive risk taking through which process performance may suffer (March, 1991).

In addition to its impact on customer acceptance, the infusion of novel knowledge is also essential for learning outcomes (Slater and Narver, 1995). Learning for subsequent projects increases if the knowledge contains new insights challenging the status quo and a wide range of views triggering different interpretations (Huber, 1991). Through experimentation and trial-and-error activities during customer cocreation projects, members acquire new, unanticipated knowledge that may contribute to the knowledge base of other projects (Blazevic and Lievens, 2004). Knowledge spillovers from customer cocreation projects may even spark entire new products and process innovations (Thomke and von Hippel, 2002). As a result, it is hypothesized:

H3: Customer cocreation of novel knowledge has (a) a curvilinear effect (i.e., an inverted U-shape) on customer acceptance and (b) a positive linear effect on learning success.

Impact of knowledge costs. Large time and money expenditures to generate and use cocreated knowledge have opposite effects on customer acceptance and learning success. First, in many markets, especially businessto-consumer (B2C), which has a large number of customers, it is difficult to identify and recruit adequate customers for cocreation (Luethje and Herstatt, 2004). As a result, the identification, recruitment, and motivation of customers entail significant human and financial efforts. At the same time, the difficulty increases the probability that firms misunderstand customers' needs and fail to satisfy them. Furthermore, firms tend to redeem high costs, in the case of cocreation, to accomplish their profit goals. Hence, the developed product is launched at a relatively higher price, which typically lowers its adoption by customers.

Second, costly cocreation has positive outcomes for learning because acquiring new skills and updating knowledge is a complex process that demands time and money (Amabile et al., 1996). Some firms invest significant amounts in developing new platforms to engage customers in knowledge generation. For example, Nokia's beta testing community nokiabetalabs.com brings customers and development teams together to prototype and improves new products in a virtual environment. Monitoring, interaction, and assistance for the community members demands significant investment in the infrastructure and human resources. While many new product ideas and features never make it to the market place, Nokia's developer teams may obtain a better understanding of customers' needs that will be useful for later innovation projects. Firms learn from developing more prototypes of new products because they provide a clearer, more realistic picture and enable tests of various configurations; yet they are often costly to produce (Thomke and von Hippel, 2002). Therefore, the following hypothesis can be deduced:

H4: Customer cocreation of costly knowledge leads to (a) lower customer acceptance and (b) greater learning success.

\section{Customer Determinants and Customer Cocreated Knowledge}

In general, the customer's role during a firm's innovation process depends on the characteristics of the customers and their relationship with the firm. Both perspectives represent enduring research streams in marketing and management. Innovation management research highlights the usefulness of involving customers with lead user characteristics to develop new products (von Hippel, 1986). Relationship marketing studies (Morgan and Hunt, 1994) instead argue that the closeness in the customer-firm relationship determines the exchange, creation, and use of knowledge (Ballantyne, 2004). These arguments entail distinct effects on the customer cocreated knowledge (Piller and Ihl, 2009).

Impact of lead user characteristics. Customers with lead user characteristics are a subset of customers who experience market needs earlier than most of the market and profit greatly from innovations that address those needs (von Hippel, 1986). These lead users possess high levels of usage expertise because of their frequent use of products, technical knowledge, and openness to innovation (Luethje and Herstatt, 2004; Schreier and Pruegl, 2008). Studies have illustrated their ability to contribute important product improvements (Franke and Shah, 2003) and to develop products that are ready for the market (Luethje and Herstatt, 2004) and commercially attractive (Franke et al., 2006).

It is hypothesized that knowledge cocreation with these lead users should produce useful and innovative ideas, but at high cost. First, lead users can provide analyses of usage problems and suggest appropriate solutions for innovation projects (von Hippel, 1986). Their technical understanding and knowledge positions them uniquely to cocreate knowledge that is comprehensible for the innovation teams and can be easily integrated into 
new products (Luethje and Herstatt, 2004; Schreier and Pruegl, 2008). Second, lead users are ahead of others in adopting new products and appreciate innovation (von Hippel, 2005). They "live in the future" (Luethje and Herstatt, 2004), as they experience today what other users will experience months or years later. Hence, their knowledge is more novel and original compared with nonlead users. Despite these benefits though, the identification and integration of lead users is complex, time consuming, and expensive (Olson and Bakke, 2001). The process involves multiple steps, including determining industry trends and generating a list of lead users. They are scarce in most industries, and firms need to convince them and often offer them financial incentives to cocreate with the focal firm instead of its competitors. Consequently, following hypothesis is established:

H5: Customers' lead user characteristics lead to greater (a) relevance, (b) novelty, and (c) costs of customer cocreated knowledge.

Impact of closeness of the customer-firm relationship. Over time and through shared experiences, firms and customers become familiar with the other's goals and develop a mutual understanding and interpretative schema. They develop a closeness in the customer-firm relationship where both parties trust each other, share resources and responsibilities, and grow social bonds between them (Morgan and Hunt, 1994; Sivadas and Dwyer, 2000). Studies about collaboration in the context of innovation demonstrate that closeness stimulates knowledge acquisition and utilization (Rindfleisch and Moorman, 2001), enables effective communication (Madhavan and Grover, 1998), and avoids misunderstandings and conflicts (Sivadas and Dwyer, 2000). Firms and customers with a close relationship are also more prone to bundle their complementary knowledge to accomplish goals that they could not have achieved alone (Rindfleisch and Moorman, 2001).

It is hypothesized that through close relationships, firms and customers can cocreate knowledge at a low cost, although it may contain few new or surprising insights. Over time in a business relationship, firms and customers develop an understanding of each others' needs and a shared language; both enable the customization and transfer of relevant knowledge (Hansen, 1999). As a result, close relationships should provide a better fit between the created knowledge and the needs of the firms' projects. However, they also may inhibit the development of novel knowledge. The literature on social relationships argues that although close customers are motivated to share and cooperate, they cannot provide access to surprising or diverse information (Granovetter, 1973). These customers are exposed to similar influences and sources of knowledge as the firm and hence the knowledge overlaps considerably.

Finally, close customer-firm relationships are associated with trust, which enables partners to work out difficulties and conflicts (Sivadas and Dwyer, 2000). This trust reduces the need for formal coordination efforts or monitoring mechanisms, which enables more costefficient customer cocreation (Ballantyne, 2004; Piller and Ihl, 2009). The following hypothesis is formulated:

\section{H6: The closeness of the customer-firm relationship leads to (a) greater relevance, (b) lower novelty, and (c) lower costs of customer cocreated knowledge.}

\section{Communication Channels and Customer Cocreated Knowledge}

Customer cocreation essentially is a communication process about innovation-related issues (e.g., new ideas, customer needs, project aims) between customers and a firm's innovation team members. This process takes place through different communication channels, which connect sender and receiver (Ballantyne, 2004). Prior studies on media richness (Daft and Lengel, 1986), collaborative communication (Mohr, Fisher, and Nevin, 1996), and information utility (Moenaert and Souder, 1996) demonstrate that the outcomes of communication processes depend on the characteristics of the communication channel. Choosing an adequate communication channel is a critical skill of managers (Daft and Lengel, 1986) because their choice may alter the meaning of the message and influence the communication outcome (Daft and Lengel, 1986; Sproull and Kiesler, 1986). Communication channels vary significantly in at least two key abilities, that is, to transfer the message comprehensively (i.e., richness) and to reduce geographical and temporal constraints (i.e., reach). Both can influence the creation of knowledge (Evans and Wurster, 1997; Sproull and Kiesler, 1986).

On the one hand, the knowledge creation demands the transfer of nonverbal cues, for example, facial expressions and body language, and opportunities for immediate feedback (Daft and Lengel, 1986). As a result, communication is more comprehensive through personal, nonverbal information and ad hoc discussions between sender and receiver. Both qualities ease the transfer of complex knowledge and reduce misunderstandings that can be high especially during the innovation process because novel knowledge emerges from cross-functional integration and combining knowledge from different 
sources (Moenaert and Souder, 1996). In addition, they assist in the transfer of tacit knowledge which is difficult to articulate and codify into a written message. Such knowledge is best delivered through personal and rich face-to-face channels of communication such as personal meetings, interviews, and workshops (Ganesan, Malter, and Rindfleisch, 2005).

On the other hand, knowledge creation may benefit from selecting communication channels that do not have the temporal and geographical constraints requiring sender and receiver to be present at the same time and location, respectively (Sawhney et al., 2005). The absence of such constraints reduces the temporal and monetary efforts needed for setting up meetings, harmonizing the schedules of participants, and travelling (including travel expenses). These bit-to-bit channels, for example, e-mail, are such means that offer quick and inexpensive communication (Evans and Wurster, 1997). E-mail can be used at any location with Internet access, often through mobile devices (Murray and Peyrefitte, 2007). Unlike face-to-face communication, sender and receiver do not attend the conversation at the same moment; instead, e-mail is a nonsimultaneous communication where replies to messages may be deferred (Sproull and Kiesler, 1986).

In the middle between both extremes, face-to-face versus bit-to-bit, are voice-to-voice channels, which partly combine the benefits of both. They enable immediate feedback to the sender but no transfer of nonverbal cues; at the same time, they do not require geographical but only temporal proximity. Telephone calls and conferences with customers are typical examples of voice-tovoice communication channels. Project members often use these channels to clarify issues in the course of projects and to complement their knowledge about the customer's needs (Ballantyne, 2004).

It seems that the unique abilities of the three channels position them best for supporting the creation of distinct knowledge. Although channels can influence more than one knowledge value dimension, each channel possesses unique strengths that appear most prominent in one dimension. Because of its high level of richness, face-toface seems to be most important for the value dimension of novelty to support the creative, complex, and iterative process of creating novel knowledge. The biggest advantage of bit-to-bit channels is the low cost and efficiency; hence, bit-to-bit communication is expected to be most impactful on the relationship between the customer determinants and the cost dimension. Finally, voice-to-voice is used in situations where project members want to clarify relatively explicit matters. Therefore, these channels are expected to be important for the impact on knowledge relevance.

Moderating impact of face-to-face communication on knowledge novelty. As discussed above, face-to-face channels possess a high richness, but a limited reach. Hence, face-to-face communication is expected to strengthen both the positive impact of lead users and the negative impact of close customers on knowledge novelty. First, the opportunities for immediate feedback allow partners to dig deeper into complex issues, such as unexpected insights about the customers' needs and their usage experience. Lead users need the rich communication channel to transfer their often tacit and complex knowledge, and be able to promote the resolution of ambiguous issues and in-depth learning (Daft and Lengel, 1986). Accordingly, the lead user approach tends to be implemented through face-to-face workshops or interviews (Luethje and Herstatt, 2004). Second, the obligatory physical proximity in face-to-face communication (i.e., limited reach) is likely to accentuate the strong ties and the closeness between the firm and its customers (Ganesan et al., 2005). In contrast to leaner channels, customers in face-to-face meetings tend to share more personal experiences and reach more knowledge consensus, bearing the risk of knowledge redundancy. Hence, face-to-face channels increase the knowledge overlap between customers and the firm's employees, which may accentuate the negative effects of customer-firm closeness on novelty as previously hypothesized.

\section{H7: Customer cocreation using face-to-face communica- tion leads to (a) greater knowledge novelty with lead users and (b) lower knowledge novelty with close customers.}

Moderating impact of bit-to-bit communication on knowledge cost. Bit-to-bit communication possesses a high reach, but a limited richness. Therefore, bit-to-bit channels are expected to strengthen the impact of lead users and close customers on knowledge cost. First, digital channels cannot comprehensively transfer complex messages, which are typical for discussions with lead users (Ganesan et al., 2005; von Hippel, 1986). The use of e-mail can be particularly frustrating in such situations because it does not facilitate explanations of highly detailed specifications (Murray and Peyrefitte, 2007); this may evoke misunderstandings which have to be resolved through time-consuming communication such as long e-mails or personal meetings. Second however, close customers have developed a shared language, trust, and 


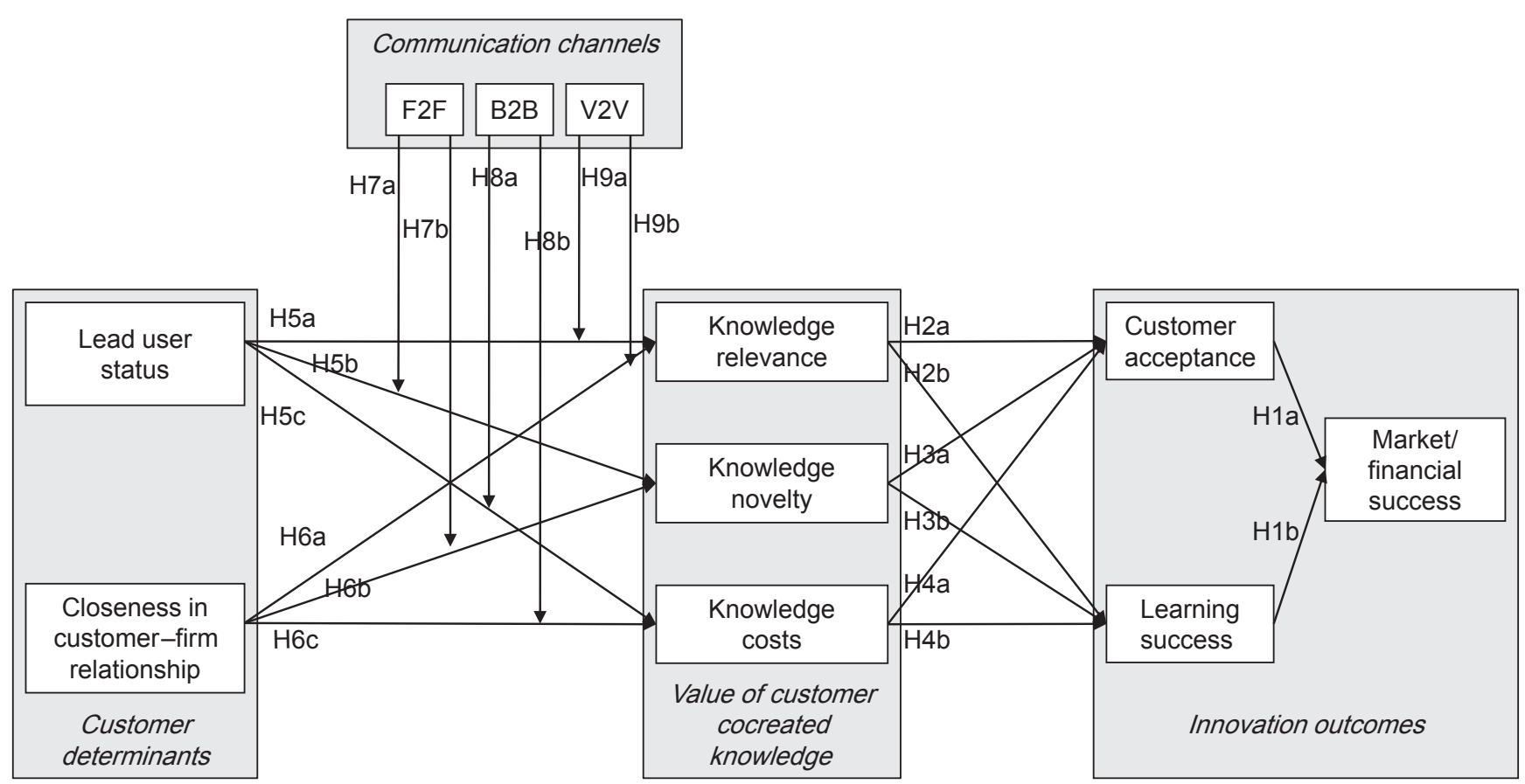

Figure 1. Conceptual Framework: Determinants and Outcomes of Customer Cocreated Knowledge

goodwill facilitating the correct understanding. In turn, this would enable the firm to seize the significant reach advantages of these channels in terms of cost (von Hippel, 2005). Hence, the following is postulated:

H8: Customer cocreation using bit-to-bit communication leads to (a) higher knowledge costs with lead users and (b) lower knowledge costs with close customers.

Moderating impact of voice-to-voice communication on knowledge relevance. Voice-to-voice channels have a medium level of reach (no geographical, but temporal proximity) and a medium level of richness (no nonverbal cues, but a real-time exchange). They allow innovators to access customers rather quickly and clarify ambiguous issues. In practice, phone calls are often used to obtain specific details that complement a firm's existing knowledge (Alam, 2002). These channels allow interactive discussion of topics and a common understanding, but the simultaneous presence of the communication participants also requires time coordination for conversations (Daft and Lengel, 1986). Voice-based channels are not bounded by geographical constraints. However, they lack the transfer of nonverbal cues (Hansen, 1999). In fact, some research argues that the absence of peripheral cues such as facial expression and gestures may be beneficial for knowledge relevance. Communication maintains the focus on issues related to the innovation task at hand, and the participants are not distracted by unrelated informa- tion (Sproull and Kiesler, 1986). While voice-to-voice channels may support the creation of relevant knowledge, previous research does not pose differential effects regarding the type of customer involved. As a result, it strengthens both the positive impact of lead users and close customers on knowledge relevance, and it can be hypothesized:

\section{H9: Customer cocreation using voice-to-voice communi- cation leads to greater knowledge relevance with (a) lead users and (b) close customers.}

Figure 1 provides the conceptual model and summarizes the research hypotheses.

\section{Method and Analysis}

\section{Sample}

As innovation is typically carried out in projects, the study's unit of analysis is the innovation project with customer cocreation activities. For the data collection, an initial list of European firms was created through cooperation with an industry association and their database of European firms active in industrial production, wholesale, retailing, and financial and technology-driven services. For the purposeful sampling, contact was made with directors of general management, marketing, research and development (R\&D), or production in order 
Table 1. Descriptive Statistics, Reliabilities, and Correlation Matrix

\begin{tabular}{|c|c|c|c|c|c|c|c|c|c|c|c|c|}
\hline & & 1 & 2 & 3 & 4 & 5 & 6 & 7 & 8 & 9 & 10 & 11 \\
\hline 1 & Lead user characteristics & .77 & & & & & & & & & & \\
\hline 2 & Closeness of customer-firm relationship & .33 & .81 & & & & & & & & & \\
\hline 3 & Knowledge novelty & .31 & .21 & .71 & & & & & & & & \\
\hline 4 & Knowledge relevance & .26 & .31 & .42 & .73 & & & & & & & \\
\hline 5 & Knowledge costs & -.09 & -.37 & -.05 & -.33 & .84 & & & & & & \\
\hline 6 & Face-to-face channels & .22 & .23 & .26 & .18 & -.10 & $n / a$ & & & & & \\
\hline 7 & Voice-to-voice channels & .32 & .36 & .25 & .09 & -.13 & .64 & $n / a$ & & & & \\
\hline 8 & Bit-to-bit channels & .34 & .39 & .21 & .00 & -.10 & .43 & .82 & $n / a$ & & & \\
\hline 9 & Customer acceptance & .22 & .36 & .15 & .40 & -.35 & .22 & .28 & .23 & .86 & & \\
\hline 10 & Market/financial success & .20 & .27 & .14 & .26 & -.16 & .13 & .07 & .07 & .58 & .86 & \\
\hline \multirow[t]{5}{*}{11} & Learning success & .33 & .24 & .35 & .27 & -.12 & .21 & .30 & .36 & .29 & .32 & .84 \\
\hline & Mean & 3.57 & 3.72 & 3.63 & 3.59 & 2.61 & 2.90 & 3.29 & 3.51 & 3.88 & 3.29 & 3.93 \\
\hline & Standard deviation & .65 & .72 & .53 & .58 & .80 & 1.13 & 1.32 & 1.49 & .64 & .71 & .58 \\
\hline & CR & .86 & .89 & .76 & .82 & .88 & $\mathrm{n} / \mathrm{a}$ & $\mathrm{n} / \mathrm{a}$ & $\mathrm{n} / \mathrm{a}$ & .90 & .92 & .88 \\
\hline & AVE & .60 & .66 & .51 & .53 & .71 & $\mathrm{n} / \mathrm{a}$ & $\mathrm{n} / \mathrm{a}$ & $\mathrm{n} / \mathrm{a}$ & .74 & .74 & .71 \\
\hline
\end{tabular}

Note: Correlations of latent variables $\geq .17$ are significant at $p<.05$; on the diagonal is the square root of AVE. CR, composite reliability; AVE, average variance extracted.

to identify projects with customer cocreation activities. The selection of customer cocreation projects included projects in which at least one customer is involved in the project work, interacts with firm's project members, and takes over tasks that are critical for the development of the new product. Reviewing activities that customers carried out and the intensity of customer-firm interaction which the respondents reported helped to control the selection. Typically, only a minority of firms engages in customer cocreation, which greatly reduces the sample pool of firms (Eurostat, 2008). The focus laid on newly developed products that were launched within the last two years to facilitate easier and more accurate recall. The contact e-mail contained a request for cooperation and a link to an online questionnaire. It was filled out either by the contacted person or by another firm's employee who participated in and was knowledgeable about the project. A reminder was sent out 10 days later if there was no reply to the initial e-mail.

After eliminating responses that lacked answers on the study's key constructs or were filled out improperly, the final sample consisted of 126 useable responses. (The cooperation with a European industry association prevented us from directly selecting firms with customer cocreation activities; instead, firms could opt in to the survey in case they ran a customer cocreation project. Large-scale innovation studies such as the European Community Innovation Study report that approximately $11 \%$ of firms cooperate with customers in their innovation process [Eurostat, 2008], which extrapolated to our pool of 3500 firms reduces our potential sample to 385 firms. Hence, the 126 responses represent a pseudo- response rate of 33\%.) Informants comprised managers working in $\mathrm{R} \& \mathrm{D}(25 \%)$, marketing (18\%), production $(16 \%)$, sales $(17 \%)$, information technology $(11 \%)$, or other fields and had a mean experience of 8.7 years in the firm. The sample contained firms of different sizes (number of employees: 20-50: 35\%; 50-500: 37\%; $>500: 28 \%$ ) and mainly operated in a business-tobusiness context $(65 \%)$. The projects were predominantly service developments (61\%), and most respondents spent considerable time per week on the project work $(<1$ hour: 3\%, 1-5 hours: $36 \%, 5-10$ hours: $26 \%, 10-20$ hours: $14 \%,>20$ hours: $21 \%$ ).

To assess potential nonresponse bias, early and late respondents were compared, as recommended by Armstrong and Overton (1977) and applied frequently (e.g., Carbonell et al., 2009). No significant $(p<.05)$ group differences for the model's research and control variables were found. Therefore, nonresponse bias does not seem to pose a serious problem for this data set.

\section{Measures}

Both reflective and formative multi-item measures were used, as well as single-item measures with 5-point Likert scales (available from the authors upon request). Table 1 contains descriptive statistics, correlation matrix, composite reliabilities (CRs), and average variance extracted (AVE) of all constructs.

Market/financial success measures the degree to which profit, return on investment, market share, and sales match the project objectives (Moorman, 1995; Veldhuizen et al., 2006). The customer acceptance items 
assess customers' satisfaction with the new product, its acceptance by customers, and its fit with customer requirements (Griffin and Page, 1996; Huang, Soutar, and Brown, 2004). Learning success measures the degree to which the experience and knowledge gained in a project serves as input and eases subsequent projects (Blazevic and Lievens, 2004).

The measurement items for the three dimensions of customer cocreated knowledge were adapted from prior studies on the value of market information (Maltz and Kohli, 1996), knowledge creation at the R\&D-marketing interface (Moenaert and Souder, 1996), satisfaction and use of information (Bailey and Pearson, 1983), and programs for new product development and launch (Im and Workman, 2004). Relevance encompasses the degree to which knowledge relates to project objectives, matches project needs, and can be integrated easily into project activities. The novelty measure captures the degree to which the knowledge gives new insights, leads to new actions, and relates to a wide range of project tasks. Costs measure time, money, and further efforts to obtain and use the cocreated knowledge.

Regarding the antecedents of customer cocreation, closeness in the customer-firm relationship was adapted from scales used by Sivadas and Dwyer (2000) and Mohr et al. (1996) that describe the degree of trust, commitment, fairness, and shared decision-making in the relationship. The second antecedent, lead user characteristics, relied on the scale developed by Morrison et al. (2004) and involve being ahead of the majority in a specific market, high expected benefit from an innovation, and customers' experience with innovation adoption. These scales are all of a reflective nature.

For measuring the use of communication channels, categories in line with prior studies were used (e.g., van Birgelen, de Ruyter, de Jong, and Wetzels, 2002), as face-to-face (e.g., meetings, personal interviews), voice-to-voice (e.g., phone calls, conference calls), and bit-to-bit (e.g., e-mail, messenger, discussion on website). Because channel use varies during the progression of a project (e.g., Alam, 2002), the communication intensity between customers and firms was captured referring to the project stages: idea generation and planning, development and design, and pilot run and launch. Each item was measured on a 6-point scale (from "never" to "daily"), similar to prior studies on interfirm communication (Maltz and Kohli, 1996). Because communication intensity across stages isfrom a theoretical point of view-not necessarily connected, the measure is formative (Diamantopoulos and Winklhofer, 2001).
Finally, additional variables to control for potential extraneous effects on innovation performance were included. These include environmental turbulence, firm size, defined as the number of employees $(1=$ less than $50,2=50-99,3=100-499,4=500-999,5=1000$ or more), the business context $(1=\mathrm{B} 2 \mathrm{C}, 2=$ business-tobusiness), and finally innovation type $(1=$ product, $2=$ service). The questionnaire was pretested with 28 members of different innovation projects, which led to some minor refinements and validation of the survey instrument.

\section{Analysis}

A partial least squares (PLS) estimation approach was used to test the theoretical model. This structural equation modeling (SEM) approach offers several advantages over covariance-based approaches, especially when the sample size is relatively small and the research model contains both reflective and formative latent constructs and moderated relationships (Hulland, 1999). All indicators were standardized to ease interpretation of their effects. To test the curvilinear effects, items were meancentered, and a quadratic term for each item was created, then the regular indicators and their quadratic terms were added to the equation. To include the formative measures pertaining to the communication channels, product indicators were created that could reflect the latent interaction variables by multiplying the main effect scales with the interaction scales. Significance of the parameters was assessed through bootstrapping.

\section{Results}

\section{Measurement Model}

In PLS, the adequacy of the measurement models is tested through various checks (Hulland, 1999). Scale reliability was examined through the loadings of the items on their respective latent factors. The results indicated loadings of greater than .5, which suggested sufficient reliability. For the CR indicator ranged from .76 to .92 and thus exceeded the recommended minimum of .7 (Fornell and Larcker, 1981). Also, the amount of AVE, ranging from .51 to .74 , exceeded its recommended minimum of .5 (Bagozzi and Yi, 1988). However, to evaluate the adequacy of formative scales, tests of internal consistency and reliability are inappropriate (Diamantopoulos and Winklhofer, 2001) because eliminating items from these formative constructs could decrease the domain of the constructs. To assess the discriminant validity of each 
construct, the square root of the AVE exceeded the construct's correlations with other constructs (Fornell and Larcker, 1981); all constructs satisfied this criterion. Also, all correlations among the reflective scales were significantly less than 1 , in further support of discriminant validity (Bagozzi and Yi, 1988).

Because the survey responses came from single informants, common method variance bias was assessed using three procedures (Podsakoff, MacKenzie, Lee, and Podsakoff, 2003). First, Harman's one-factor test with principal component analysis (unrotated and with varimax rotation) was used. Eleven factors emerged to account for $69 \%$ of the total variance of which the first (largest) factor did not capture a majority $(21 \%)$. These results suggested that the variables did not form one single higher-order factor that could account for the majority of the covariance in the measures. Second, following Lindell and Whitney's (2001) recommendation, a marker variable from the key constructs was selected, in this case bit-to-bit communication, that has the smallest positive correlation $(r=.07$, n.s.; see Table 1) with market/financial innovation success, the main outcome variable. Its correlation is used to partial out its effects from other correlations and to assess the extent of common method variance. The initially significant correlations of the predictions remain significant and of similar magnitude after the adjustment. Bias due to common method variance may not pose a serious threat to the study's findings.

\section{Structural Model}

PLS is designed to maximize predictions, emphasizes the variance explained in the dependent variables, and hence, in contrast to covariance-based SEM techniques, does not provide sound model fit measures derived from its $\chi^{2}$ statistic (Hulland, 1999). Instead, the prediction-oriented $R^{2}$ variances explained, the signs, and the significances of the path coefficients were used to assess the model's nomological validity. The variance explained of our innovation outcomes are .39 for financial success, .26 for customer acceptance, and .16 for learning success. For the value dimensions of cocreated knowledge, they are .19 for relevance, .21 for novelty, and .18 for costs. The model's global goodness of fit based on the $R^{2}$ statistics is .40 (Tenenhaus, Vinzi, Chatelin, and Lauro, 2005). The control variables have no significant effect on innovation success.

The standardized path estimates and $t$-values suggest conclusions about each hypothesis (see Table 2). Results reveal significant impact of customer acceptance (H1a) and learning success (H1b) on market/financial success. Customer cocreation of relevant knowledge exhibits a positive effect on customer acceptance (H2a) and on

Table 2. Summary of Hypotheses Testing

\begin{tabular}{|c|c|c|c|c|}
\hline Hypothesis & Paths & Directions & Model Estimates & Results \\
\hline $\mathrm{H} 1 \mathrm{a}$ & Customer acceptance $\rightarrow$ Market/financial success & + & $.52 * * * *$ & Supported \\
\hline $\mathrm{H} 1 \mathrm{~b}$ & Learning success $\rightarrow$ Market/financial success & + & $.18 * *$ & Supported \\
\hline $\mathrm{H} 2 \mathrm{a}$ & Relevance $\rightarrow$ Customer acceptance & + & $.33 * * * *$ & Supported \\
\hline $\mathrm{H} 2 \mathrm{~b}$ & Relevance $\rightarrow$ Learning success & + & $.16^{* *}$ & Supported \\
\hline $\mathrm{H} 3 \mathrm{a}$ & Novelty $\rightarrow$ Customer acceptance & $\cap(+)$ & $-.22 * *($ n.s. $)$ & Supported \\
\hline $\mathrm{H} 3 \mathrm{~b}$ & Novelty $\rightarrow$ Learning success & + & $.28 * * *$ & Supported \\
\hline $\mathrm{H} 4 \mathrm{a}$ & Costs $\rightarrow$ Customer acceptance & - & $-.22 * * *$ & Supported \\
\hline $\mathrm{H} 4 \mathrm{~b}$ & Costs $\rightarrow$ Learning success & + & n.s. & Not supported \\
\hline H5a & Lead user characteristics $\rightarrow$ Relevance & + & $.25 * * *$ & Supported \\
\hline $\mathrm{H} 5 \mathrm{~b}$ & Lead user characteristics $\rightarrow$ Novelty & + & $.26 * * *$ & Supported \\
\hline $\mathrm{H} 5 \mathrm{c}$ & Lead user characteristics $\rightarrow$ Costs & + & n.s. & Not supported \\
\hline H6a & Closeness in relationship $\rightarrow$ Relevance & + & $.27 * * * *$ & Supported \\
\hline $\mathrm{H} 6 \mathrm{~b}$ & Closeness in relationship $\rightarrow$ Novelty & - & n.s. & Not supported \\
\hline H6c & Closeness in relationship $\rightarrow$ Costs & - & $-.44 * * * *$ & Supported \\
\hline $\mathrm{H} 7 \mathrm{a}$ & $\mathrm{F} 2 \mathrm{~F} \times$ Lead user characteristics $\rightarrow$ Novelty & + & $.15^{*}$ & Supported \\
\hline $\mathrm{H} 7 \mathrm{~b}$ & F2F $\times$ Closeness in relationship $\rightarrow$ Novelty & - & $-.27 * * *$ & Supported \\
\hline $\mathrm{H} 8 \mathrm{a}$ & B2B $\times$ Lead user characteristics $\rightarrow$ Costs & + & $.14^{*}$ & Supported \\
\hline $\mathrm{H} 8 \mathrm{~b}$ & B2B $\times$ Closeness in relationship $\rightarrow$ Costs & - & $-.20 * *$ & Supported \\
\hline H9a & $\mathrm{V} 2 \mathrm{~V} \times$ Lead user characteristics $\rightarrow$ Relevance & + & $.19 * *$ & Supported \\
\hline $\mathrm{H} 9 \mathrm{~b}$ & $\mathrm{~V} 2 \mathrm{~V} \times$ Closeness in relationship $\rightarrow$ Relevance & + & n.s. & Not supported \\
\hline
\end{tabular}

$* p<.10, * * p<.05, * * * p<.01, * * * * p<.001 . \mathrm{F} 2 \mathrm{~F}$, face-to-face; $\mathrm{B} 2 \mathrm{~B}$, bit-to-bit; $\mathrm{V} 2 \mathrm{~V}$, voice-to-voice. 
learning success $(\mathrm{H} 2 \mathrm{~b})$. The quadratic term for knowledge novelty is significantly negative for customer acceptance (H3a) while its simultaneous linear effect is nonsignificant, confirming the predicted curvilinear effect of novel knowledge. Yet, novelty also demonstrates a linear positive effect on learning success (H3b). (Further tests did not reveal a curvilinear effect of novelty on learning success, confirming our linear prediction.) Costs exert a negative effect on customer acceptance (H4a), but contrary to the expectation, no significant relationship with learning success (H4b) was found. Involving customers with lead user characteristics significantly increases the relevance (H5a) and novelty (H5b) but not the costs $(\mathrm{H} 5 \mathrm{c})$ of customer cocreated knowledge. Closeness in the customer-firm relationship also fosters the creation of relevant knowledge (H6a) at low costs (H6c), but it does not reveal a significant effect on novelty (H6b). As predicted, face-to-face communication accentuates the negative relationship between novelty and customer-firm closeness (H7b) and at the same time, the positive relationship between novelty and lead user characteristics (H7a). Bit-to-bit communication increases costs when lead users are involved (H8a) but at the same time reduces the costs of knowledge creation in close customer-firm relationships (H8b). Contrary to the expectations, voice-to-voice communication does not significantly strengthen the creation of relevant knowledge when customers and firms have a close relationship (H9b) but only when customers possess lead user characteristics (H9a). (An alternative model was analyzed where all three communication channels moderate the relationship of customer determinants with all knowledge dimensions. Our results revealed only one additional significant relationship, that is, $\mathrm{V} 2 \mathrm{~V} \times$ Relationship Closeness $\rightarrow$ Relevance. Because of these limited findings and the theoretical arguments stated earlier, our model was kept that associates one communication channel with one knowledge value dimension.)

\section{Discussion}

In recent years, an increasing number of firms has attempted to tap into the knowledge, skills, and interests of their customers to cocreate new products (Fuchs and Schreier, 2011; Nambisan and Baron, 2009; Sawhney et al., 2005). Addressing a top priority in innovation and marketing research (Di Benedetto, 2012; MSI, 2010), this research develops and quantitatively validates a conceptual framework of the drivers and outcomes of customer cocreated knowledge. The investigation of projects, cus- tomers, and communication channels that stimulate successful cocreation provides a finer-grained understanding of the phenomenon.

\section{Research Implications}

Our study contributes to innovation and marketing theory by formalizing service-dominant logic, sometimes criticized as being vague. Our conceptualization of customer cocreation of knowledge is closely aligned to the logic's foundational premises (Vargo and Lusch, 2004). While the centrality of knowledge is concurrent with the knowledge-based view, customer cocreation enriches it by integrating customers as a knowledge resource that is beyond the firm's control. The study focuses on the firm as the cocreation beneficiary and hence, complements recent studies which examine cocreation outcomes from the customer perspective (e.g., Franke et al., 2010; Fuchs and Schreier, 2011). Using a structural approach, three key value dimensions of customer cocreated knowledge, that is, relevance, novelty, and costs, are identified. Research typically omits the latter one (Carbonell et al., 2009; Hoyer et al., 2010), although costs are an important limitation for interorganizational innovation activities (Eurostat, 2008). This study conceptualizes and empirically tests a research framework for a fine-grained investigation of customer cocreation.

A second contribution of this study is the empirical analysis of the distinct effects of customer cocreated knowledge on innovation success. Previous research has been equivocal regarding its drivers and impact, tended to be limited to a single context (e.g., Nambisan and Baron, 2009), or focused on qualitative data (e.g., Blazevic and Lievens, 2008). Our empirical findings indicate that customer cocreation of relevant knowledge has a positive impact on any success outcome. Through interaction, firms obtain project-relevant knowledge on customers' needs or feedback on prototypes. In contrast, the effects of novel knowledge are more complex. New ideas and surprising insights are invariably critical for the development of new products in order to develop distinctive product features and stimulate learning for future projects. While an extremely high degree of novelty may provoke customers' dissatisfaction as customers need to alter their routines to use new product features that are beyond their current scope of experience (Alba and Hutchinson, 1987; Knudsen, 2007), the firm's learning always gains from greater novelty. The integration of learning outcomes enriches empirical research on knowledge cocreation in innovation projects, which tends to view learning as a driver of project success (e.g., 
Edmondson and Nembhard, 2009; Knudsen, 2007) rather than as an outcome itself. Furthermore, negative innovation outcomes may stem from high difficulties in knowledge cocreation and associated time and monetary efforts to overcome them. However, contrary to managers' arguments and our expectations (Eurostat, 2008), costs show only limited effect in our model. Compared with novelty and relevance, perception of costs may be more difficult to assess for survey respondents as costs are typically captured in concrete units such as hours or dollars. This might also explain the lower mean and stronger dispersion of the scale. Collectively, these findings reveal a more complex pattern of customers' contribution to innovation than in previous research and the need to balance customers' input with other knowledge sources.

Another contribution pertains to the customer determinants of customer cocreation, which compares arguments of research on relationship marketing and on lead users. The empirical findings confirm earlier research (Schreier and Pruegl, 2008) that involving customers with lead user characteristics increases the novelty and relevance of cocreated knowledge. However, contrary to our expectations (Olson and Bakke, 2001), the extended process required to identify lead users does not produce a direct linear effect on costs. A supplementary analysis discovered a curvilinear effect, such that a medium level of lead user characteristics appears to invoke the highest costs. The identification of second-tier lead users may be more costly than that of first-tier lead users, who are probably known as industry-wide experts because of their conference participation or publications (von Hippel, 2005). In contrast, closeness in the customer-firm relationship fosters knowledge that well suits the project activities and is produced at a low cost. Surprisingly, there was no evidence that close ties between firms and customers alone inhibit the development of novel knowledge (Piller and Ihl, 2009). Yet, this occurs when communication relies on face-to-face channels that accentuate the closeness and potential negative effects of knowledge redundancies, advocating for the context consideration during customer cocreation. An additional analysis shows a significant interaction of the lead user characteristics and relationship closeness on customer cocreated knowledge, that is, a negative effect on novelty $(\beta=-.27, p<.01)$. It seems that benefits of both customer determinants cannot be combined. For example, a lead user that cooperates with a firm for a longer time would assimilate. This may increase knowledge overlap and decrease the probability of creating very novel ideas.

Finally, this research demonstrates the pivotal impact of the choice of communication channels that have distinct, partly oppositional influences on customer cocreation. While prior studies on customer cocreation do not distinguish between channels (e.g., Carbonell et al., 2009; Lau et al., 2010) or focus on one (Mahr and Lievens, 2012; Poetz and Schreier, 2012), this research probes into differences between cocreation via face-toface, voice-to-voice, and bit-to-bit channels. The channels vary in their abilities to transfer the message comprehensively ("richness") and to cross geographical and temporal boundaries ("reach"). The three channels increase or decrease the effectiveness of customer cocreation depending on the nature of the customer involved. Face-to-face channels stimulate the creation of novel knowledge because of the transfer of verbal and nonverbal cues, but they also accentuate familiarity in a customer-firm relationship to such an extent that this inhibits the generation of unexpected insights. The cost advantage of bit-to-bit channels can be leveraged when a firm and its customers possess a mutual understanding and trust like in close relationships. In contrast, lead users are purposefully selected from other markets (Luethje and Herstatt, 2004) and do not share interpretative schemes with the firm. This may lead to confusion and difficulties in communication when using bit-to-bit channels that only transfer written information. The opposite effects of customer characteristics on costs when using bit-to-bit communication provide a more fine-grained picture of the typically assumed cost advantages of these channels (Nambisan and Nambisan, 2008). Overall, our results call attention to the need for a simultaneous consideration of communication channels and customer characteristics in future research efforts on customer cocreation.

\section{Managerial Implications}

The findings have several implications for the growing number of firms that expand their innovation activities through customer cocreation (EIU, 2009). Before investing in it, managers need to review the specific knowledge demands of the innovation project. It appears that customer cocreated knowledge provides most value through its customization to specific project tasks and its moderate degree of originality. Such knowledge demands tend to emerge in the development of products within the firm's current domain rather than in radically new products. Nonetheless, for the latter one, a cocreating customer may serve as promoter and tester during the product's commercialization, during which firms rely on practical, hands-on knowledge to ensure a timely, successful launch (Nambisan and Nambisan, 2008). Manag- 
ers need to be aware of the opportunities and limitations of knowledge creation with customers. Indeed, unrealistic expectations are a main reason why such initiatives fail (Christensen and Bower, 1996).

Moreover, managers should deliberately select and alternate customers for cocreation activities. Firms tend to select customers from long-lasting business relationships because of mutual trust and convenient access to them (Alam, 2002). While such customers can clearly be beneficial, the stimulation of new insights requires customers who are ahead of a market's majority. To benefit from trustworthy relationships and the customers' innovativeness, our findings suggest seeking multiple customers with either quality rather than customers that capture both. Integrating multiple customers with different characteristics takes into account the dynamics of a relationship because the participation in several firm projects may turn a lead user into a customer with a close relationship. At the same time, a purposeful rotation of cocreating customers and the collaborating project members may attenuate negative effects of knowledge overlaps because of close relationships.

A final practical implication relates to the effective usage of communication channels and its dependence on the customers involved. Firms should advise their innovation teams about which channels to employ to enhance innovation outcomes. If the firm needs to obtain new ideas, face-to-face channels may be beneficial with lead users but counterproductive with close customers. Practically, the selection of communication channels is often connected with a particular customer because of a shared history or location. Firms are advised to break up this connection and consider the type of customers and intended knowledge outcomes when planning the project. Development of a mutual understanding (e.g., through firm visit), shared language (e.g., through a codebook of specific terms), and trust (e.g., through sharing of resources) in the initial stage of a project could improve collaboration with customers who are unfamiliar with a firm's needs and culture. The common base is especially important for knowledge development through digital channels and for the reduction of overload with irrelevant information.

\section{Directions for Further Research}

Several limitations of this study may suggest additional research directions. First, this study focuses on three value dimensions of customer cocreated knowledge. Future studies could include other dimensions such as knowledge credibility or accuracy that may also affect the creation of knowledge and its use (Maltz and Kohli, 1996). The integration of costs and difficulties of customer cocreation is intriguing from a managerial and scholarly point of view. However, costs are assessed by a subjective rather than an objective measure. Future studies may experimentally manipulate monetary or temporal investments to obtain customers' knowledge.

Another extension of our research could be to explore the effectiveness of complementary employment of communication channels. While this study focuses on their distinct usage, the high correlations among the channels used (see Table 1), in particular between voice-to-voice and bit-to-bit (.82) as well as face-to-face (.64), point toward a simultaneous employment of channels. Further research might delve the sequential usage and the synergies of communication channels. For example, understanding to what extent bit-to-bit communication may compensate for weaknesses of face-to-face communication would be an interesting future research avenue.

From a methodological perspective, this paper contributes to scant quantitative research by applying a crosssectional survey approach that may be criticized for its moderate sample size and its proneness to common method bias. Although the use of externally oriented constructs and established scales, as well as the satisfactory experience level of our respondents help minimize potential negative effects (Rindfleisch, Malter, Ganesan, and Moorman, 2008), a large-scale longitudinal design with multiple respondents could cross-validate our findings.

\section{References}

Alam, I. 2002. An exploratory investigation of user involvement in new service development. Journal of the Academy of Marketing Science 30 (3): 250-61.

Alba, J. W., and J. W. Hutchinson. 1987. Dimensions of expertise. Journal of Consumer Research 13 (4): 411-54.

Amabile, T. M., R. Conti, H. Coon, J. Lazenby, and M. Herron. 1996. Assessing the work environment for creativity. Academy of Management Journal 39 (5): 1154-84.

Armstrong, J. S., and T. S. Overton. 1977. Estimating nonresponse bias in mail surveys. Journal of Marketing Research 14 (3): 396-402.

Bagozzi, R. P., and Y. Yi. 1988. On the evaluation of structural equation models. Journal of the Academy of Marketing Science 16 (1): 74-94.

Bailey, J. E., and S. W. Pearson. 1983. Development of a tool for measuring and analyzing computer user satisfaction. Management Science 29 (5): $530-45$.

Ballantyne, D. 2004. Dialogue and its role in the development of relationship specific knowledge. Journal of Business \& Industrial Marketing 19 (2): 114-23.

Blazevic, V., and A. Lievens. 2004. Learning during the new financial service innovation process: Antecedents and performance effects. Journal of Business Research 57 (4): 374-91.

Blazevic, V., and A. Lievens. 2008. Managing innovation through customer coproduced knowledge in electronic services: An exploratory study. Journal of the Academy of Marketing Science 36 (1): 138-51. 
Carbonell, P., A. I. Rodriguez-Escudero, and D. Pujari. 2009. Customer involvement in new service development: An examination of antecedents and outcomes. Journal of Product Innovation Management 26 (5): 536-50.

Christensen, C. M., and J. L. Bower. 1996. Customer power, strategic investment, and the failure of leading firms. Strategic Management Journal 17 (3): 197-218.

Cohen, W. M., and D. A. Levinthal. 1990. Absorptive capacity: A new perspective on learning and innovation. Administrative Science Quarterly 35 (1): 128-52.

Daft, R. L., and R. H. Lengel. 1986. Organizational information requirements, media richness and structural design. Management Science 32 (5): 554-71.

Di Benedetto, C. A. 2012. The JPIM thought leadership symposium. Journal of Product Innovation Management 29 (3): 344-48.

Diamantopoulos, A., and H. M. Winklhofer. 2001. Index construction with formative indicators: An alternative to scale development. Journal of Marketing Research 38 (2): 269-77.

Edmondson, A. C., and I. M. Nembhard. 2009. Product development and learning in project teams: The challenges are the benefits. Journal of Product Innovation Management 26 (2): 123-38.

EIU. 2009. Fertile ground: Cultivating a talent for innovation. London: Economist Intelligence Unit, The Economist.

Eurostat. 2008. Science, technology and innovation in Europe. Luxembourg: European Commission.

Evans, P. B., and T. S. Wurster. 1997. Strategy and the new economics of information. Harvard Business Review 75 (5): 70-82.

Fornell, C., and D. F. Larcker. 1981. Structural equation models with unobservable variables and measurement error: Algebra and statistics. Journal of Marketing Research 18 (3): 382-88.

Franke, N., and F. Piller. 2004. Value creation by toolkits for user innovation and design: The case of the watch market. Journal of Product Innovation Management 21 (6): 401-15.

Franke, N., M. Schreier, and U. Kaiser. 2010. The "I designed it myself" effect in mass customization. Management Science 56 (1): 125-40.

Franke, N., and S. Shah. 2003. How communities support innovative activities: An exploration of assistance and sharing among end-users. Research Policy 32 (1): 157-78.

Franke, N., E. von Hippel, and M. Schreier. 2006. Finding commercially attractive user innovations: A test of lead user theory. Journal of Product Innovation Management 23 (4): 301-15.

Fuchs, C., and M. Schreier. 2011. Customer empowerment in new product development. Journal of Product Innovation Management 28 (1): $17-32$

Ganesan, S., A. J. Malter, and A. Rindfleisch. 2005. Does distance still matter? Geographic proximity and new product development. Journal of Marketing 69 (4): 44-60.

Granovetter, M. 1973. The strength of weak ties. American Journal of Sociology 78 (6): 1360-80.

Griffin, A., and J. R. Hauser. 1993. The voice of the customer. Marketing Science 12 (1): 1-27.

Griffin, A., and A. L. Page. 1996. PDMA success measurement project: Recommended measures for product development success and failure. Journal of Product Innovation Management 13 (6): 478-96.

Hansen, M. T. 1999. The search-transfer problem: The role of weak ties in sharing knowledge across organization subunits. Administrative Science Quarterly 44 (1): 82-111.

Henard, D. H., and D. M. Szymanski. 2001. Why some new products are more successful than others. Journal of Marketing Research 38 (3): $362-75$.

Hoyer, W. D., R. K. Chandy, M. Dorotic, M. Krafft, and S. S. Singh. 2010. Consumer cocreation in new product development. Journal of Service Research 13 (3): 283-96.
Huang, X., G. N. Soutar, and A. Brown. 2004. Measuring new product success: An empirical investigation of Australian SMEs. Industrial Marketing Management 33 (2): 117-23.

Huber, G. P. 1991. Organizational learning: The contributing processes and the literatures. Organization Science 2 (1): 88-115.

Hulland, J. 1999. Use of partial least squares (PLS) in strategic management research: A review of four recent studies. Strategic Management Journal 20 (2): 195-204.

Im, S., and J. J. P. Workman. 2004. Market orientation, creativity, and new product performance in high-technology firms. Journal of Marketing 68 (2): 114-32

Jaworski, B., and A. K. Kohli. 1993. Market orientation: Antecedents and consequences. Journal of Marketing 57 (3): 53-70.

Jaworski, B., and A. K. Kohli. 2006. Co-creating the voice of the customer. In The service-dominant logic of marketing: Dialog, debate, and directions, ed. R. F. Lusch and S. L. Vargo, 109-17. Armonk, NY: M.E. Sharpe.

Joshi, A. W., and S. Sharma. 2004. Customer knowledge development: Antecedents and impact on new product performance. Journal of Marketing 68 (4): 47-59.

Knudsen, M. P. 2007. The relative importance of interfirm relationships and knowledge transfer for new product development success. Journal of Product Innovation Management 24 (2): 117-38.

Kristensson, P., P. R. Magnusson, and J. Matthing. 2002. Users as a hidden resource for creativity: Findings from an experimental study on user involvement. Creativity and Innovation Management 11 (1): 55-61.

Lau, A. K. W., E. Tang, and R. C. M. Yam. 2010. Effects of supplier and customer integration on product innovation and performance: Empirical evidence in Hong Kong manufacturers. Journal of Product Innovation Management 27 (5): 761-77.

Lindell, M. K., and D. J. Whitney. 2001. Accounting for common method variance in cross-sectional research designs. Journal of Applied Psychology 86 (1): 114-21.

Luethje, C., and C. Herstatt. 2004. The lead user method: An outline of empirical findings and issues for future research. $R \& D$ Management 34 (5): 553-68.

Madhavan, R., and R. Grover. 1998. From embedded knowledge to embodied knowledge: New product development as knowledge development. Journal of Marketing 62 (4): 1-12.

Magnusson, P. R. 2009. Exploring the contributions of involving ordinary users in ideation of technology-based services. Journal of Product Innovation Management 26 (5): 578-93.

Mahr, D., and A. Lievens. 2012. Virtual lead user communities: Drivers of knowledge creation for innovation. Research Policy 41 (1): 167-77.

Maltz, E., and A. K. Kohli. 1996. Market intelligence dissemination across functional boundaries. Journal of Marketing Research 33 (1): 47-61.

March, J. G. 1991. Exploration and exploitation in organizational learning. Organization Science 2 (1): 71-87.

Moenaert, R. K., and W. E. Souder. 1996. Context and antecedents of information utility at the $\mathrm{R} \& \mathrm{D} / \mathrm{marketing}$ interface. Management Science 42 (11): 1592-610.

Mohr, J., R. Fisher, and R. J. Nevin. 1996. Collaborative communication in interfirm relationships: Moderating effects of integration and control. Journal of Marketing 60 (3): 103-15.

Moorman, C. 1995. Organizational market information processes: Cultural antecedents and new product outcomes. Journal of Marketing Research 32 (3): 318-35.

Moorman, C., and R. J. Slotegraaf. 1999. The contingency value of complementary capabilities in product development. Journal of Marketing Research 36 (2): 239-57.

Morgan, R. M., and S. D. Hunt. 1994. The commitment-trust theory of relationship marketing. Journal of Marketing 58 (3): 20-38.

Morrison, P. D., J. H. Roberts, and D. F. Midgley. 2004. The nature of lead users and measurement of leading edge status. Research Policy 33 (2): 351-62. 
MSI. 2010. 2010-2012 research priorities. Cambridge, MA: Marketing Science Institute.

Murray, S. R., and J. Peyrefitte. 2007. Knowledge type and communication media choice in the knowledge transfer process. Journal of Managerial Issues 19 (1): 111-33.

Nambisan, S., and R. A. Baron. 2009. Virtual customer environments: Testing a model of voluntary participation in value co-creation activities. Journal of Product Innovation Management 26 (4): 388-406.

Nambisan, S., and P. Nambisan. 2008. How to profit from a better "virtual customer environment." Sloan Management Review 49 (3): 53-61.

O'Hern, M. S., and A. Rindfleisch. 2010. Customer co-creation: A typology and research agenda. In Review of marketing research, Vol. 6, ed. N. K. Malhotra, 84-106. Armonk, NY: M.E. Sharpe.

Olson, E. L., and G. Bakke. 2001. Implementing the lead user method in a high technology firm: A longitudinal study of intentions versus actions. Journal of Product Innovation Management 18 (6): 388-95.

Piller, F., and C. Ihl. 2009. Open innovation with customers. Aachen: RWTH Aachen University.

Podsakoff, P. M., S. B. MacKenzie, J.-Y. Lee, and N. P. Podsakoff. 2003. Common method biases in behavioral research: A critical review of the literature and recommended remedies. Journal of Applied Psychology 88 (5): 879-903.

Poetz, M. K., and M. Schreier. 2012. The value of crowdsourcing: Can users really compete with professionals in generating new product ideas? Journal of Product Innovation Management 29 (2): 245-56.

Prahalad, C. K., and V. Ramaswamy. 2004. Co-creating unique value with customers. Strategy \& Leadership 32 (3): 4-9.

Rindfleisch, A., A. J. Malter, S. Ganesan, and C. Moorman. 2008. Crosssectional versus longitudinal survey research: Concepts, findings, and guidelines. Journal of Marketing Research 45 (3): 261-79.

Rindfleisch, A., and C. Moorman. 2001. The acquisition and utilization of information in new product alliances: A strength-of-ties perspective. Journal of Marketing 65 (2): 1-18.
Sawhney, M., G. Verona, and E. Prandelli. 2005. Collaborating to create: The Internet as a platform for customer engagement in product innovation. Journal of Interactive Marketing 19 (4): 4-17.

Schreier, M., and R. Pruegl. 2008. Extending lead-user theory: Antecedents and consequences of consumers' lead userness. Journal of Product Innovation Management 25 (4): 331-46.

Sivadas, E., and F. R. Dwyer. 2000. An examination of organizational factors influencing new product success in internal and alliance-based processes. Journal of Marketing 64 (1): 31-49.

Slater, S. F., and J. C. Narver. 1995. Market orientation and the learning organization. Journal of Marketing 59 (3): 63-74.

Sproull, L., and S. Kiesler. 1986. Reducing social context cues: Electronic mail in organizational communications. Management Science 32 (11): 1492-512.

Tenenhaus, M., V. E. Vinzi, Y. M. Chatelin, and C. Lauro. 2005. PLS path modeling. Computational Statistics \& Data Analysis 48 (1): 159-205.

Thomke, S., and E. von Hippel. 2002. Customers as innovators-A new way to create value. Harvard Business Review 80 (2): 74-81.

van Birgelen, M., K. de Ruyter, A. de Jong, and M. Wetzels. 2002. Customer evaluations of after-sales service contact modes: An empirical analysis of national culture's consequences. International Journal of Research in Marketing 19 (1): 43-64.

Vargo, S. L., and R. F. Lusch. 2004. Evolving to a new dominant logic for marketing. Journal of Marketing 68 (1): 1-17.

Vargo, S. L., and R. F. Lusch. 2008. Service-dominant logic: Continuing the evolution. Journal of the Academy of Marketing Science 36 (1): 1-10.

Veldhuizen, E., E. J. Hultink, and A. Griffin. 2006. Modeling market information processing in new product development: An empirical analysis. Journal of Engineering and Technology Management 23 (4): 353-73.

von Hippel, E. 1986. Lead users: A source of novel product concepts. Management Science 32 (7): 791-805.

von Hippel, E. 2005. Democratizing innovation. Cambridge, MA: The MIT Press. 